\title{
LA IGLESIA DE LA ENCARNACIÓN DE RONDA: ECLECTICISMO ARQUITECTÓNICO Y SÍNTESIS DE CATÁSTROFES NATURALES (SS. XVI-XVIII)
}

\author{
Miguel Soto Garrido* \\ UNIVERSidAD DE MÁlaga
}

\begin{abstract}
RESUMEN
En el presente artículo realizamos una aproximación al proceso constructivo de la iglesia de la Encarnación de Ronda a la luz de las fuentes documentales y las aportaciones de los cronistas locales. La iglesia de la Encarnación de Ronda, cuyos antecedentes como espacio de culto se remontan a la época medieval, se constituyó como el principal templo de la ciudad durante la Edad Moderna. Sin embargo, su proceso constructivo, remontado a la conquista de la ciudad por los Reyes Católicos y la consagración del templo, se dilataría hasta el siglo XVIII, topándose en su camino no solo con numerosas catástrofes naturales de diversa índole que incidieron directamente en el templo, sino con dificultades varias que impedirían el efectivo funcionamiento de la fábrica hasta prácticamente el final del Antiguo Régimen.
\end{abstract}

PALABRAS CLAVE: iglesia de la Encarnación, Ronda, reino de Granada, mentalidades, Edad Moderna

*miguelsoto1977@gmail.com 
ISSN: 0212-5099

DOI: https://doi.org/10.24310/BAETICA.2018.v0i38.5525

\title{
THE CHURCH OF THE ENCARNACION OF RONDA: ECLECTICISM ARCHITECTURAL AND SYNTHESIS OF NATURAL DISASTERS (16TH-18TH)
}

\author{
Miguel Soto Garrido* \\ Universidad DE MÁlaga
}

\begin{abstract}
In this paper we make an approach to the constructive process of the Church of the Encarnación of Ronda, in the light of the documentary sources and contributions from the local chroniclers. The Church of the Encarnación of Ronda, whose background as a space of worship dates back to medieval times, was constituted as the main temple of the city during the modern age. However, its construction process, traced back into the conquest of the city by the Catholic monarchs and the consecration of the temple, would last until the 18th century. In this way, it would find various kinds of natural disasters which impacted directly on the temple, but with several difficulties which would prevent the effective functioning of the factory until practically the end of the Old Regime.
\end{abstract}

KEY WORDS: church of the Encarnacion, Ronda, kingdom of Granada, mentalities, Modern Age

*miguelsoto1977@gmail.com 


\section{APROXIMACIÓN HISTÓRICA}

La ciudad de Ronda, cobijada por distintos accidentes geográficos que le confirieron desde la Antigüedad un cierto aislamiento ${ }^{1}$, fue conquistada por los Reyes Católicos en 1485, al tiempo que se desarrollaba una guerra que haría claudicar los últimos reductos del reino nazarí de Granada ${ }^{2}$. En aquel momento Ronda, población musulmana en un punto estratégico de la comarca, poseía, tal y como era común en el urbanismo islámico, una mezquita aljama para la oración de los fieles de Alá. Tras la caída de la plaza, el templo musulmán fue objeto de una reconciliación al credo católico dentro de las dinámicas de conversión de una ciudad al mundo cristiano en todos los sentidos. Tenemos constancia de que esta tarea -de gran importancia, pues como ya ocurría en la etapa anterior, iba a pasar a vertebrar la vida ciudadana y religiosa de la urbe--, empezó su andadura ya desde momentos tempranos ${ }^{3}$. Tras la expugnación del enclave se celebró una ceremonia de consagración de la mezquita oficiada por Pedro Díaz de Toledo, capellán mayor del ejército del $\mathrm{rey}^{4}$. La advocación otorgada, a Santa María de la Encarnación, lejos de suponer una casuística, se presenta como una constante en el reino conquistado y con una carga simbólica que autores como López de Coca Castañer interpretan como el misterio de la Encarnación y la victoria cristiana sobre el Islam ${ }^{5}$.

Poco tiempo después, tras la conversión de la antigua mezquita, se iniciaría un largo proceso constructivo que se dilataría hasta el siglo XVIII, si bien aún se reconocen restos árabes en la fábrica ${ }^{6}$. Durante este tiempo Ronda vio erigirse el que sería su primer y más importante templo cristiano, sobre el que recaería la fundación de capellanías, y se convertiría en codi-

1. F. Rodríguez Martínez (1977), 472.

2. M. Acién Almansa (1977), 145-147.

3. Cabe destacar la constatación arqueológica de una basílica paleocristiana-visigoda con su respectiva zona de necrópolis, datada en los siglos VI-VII, en un espacio adyacente e inmediato a la posterior mezquita mayor y templo cristiano. Ello evidencia y resalta la importancia del carácter sagrado del recinto y su perduración como espacio del culto principal de la ciudad durante el Medievo, la Modernidad y la Edad Contemporánea. Al respecto consúltese: P. Aguayo de Hoyos y J. M. Castaño Agüllar (2000), 365-397; J. M Castaño Agüllar (2006), 140-141; A. Adroder, P. Aguayo de Hoyos, y C. Ruiz (1991), 407-412.

4. J. J. Moreti (1993), 404-405.

5. J. E. López de Coca Castañer (1977), 70-72.

6. M. D. Aguilar García (1979), 147. Son varios los restos musulmanes conservados parcialmente en la iglesia que datan del siglo XIII bajo la presencia meriní. 
ciado lugar de eterno reposo para las principales familias de la ciudad. No en vano, la iglesia se alzó en la clave de bóveda de la jerarquía eclesiástica rondeña, partiendo de los privilegios y fueros conferidos por los Reyes Católicos ${ }^{7}$. Pero, al igual que otras poblaciones, presenció los numerosos desastres naturales que azotaron a la sociedad de la Andalucía Moderna, y de los que este núcleo serrano no se vio exento. Ha de resaltarse que estas calamidades afectaron de manera singular al templo mayor de la urbe, viéndose alterado en varias ocasiones. En alguna de ellas los daños fueron asimilables y superficiales; en otras, la intensidad de los fenómenos -mayoritariamente terremotos y tormentas, junto a las distintas epidemias que afectaron de forma indirecta al diezmar la población y los fondos que podían destinarse a su reconstrucción-, hizo que fuera necesario emprender una auténtica reconstrucción de la fábrica anterior. Estos hechos nos permiten estudiar la Ronda moderna a través de la arquitectura local, otorgando a la iglesia de la Encarnación un aspecto único y totalmente genuino, fruto de sus distintas fases edilicias.

Así, el primitivo templo que vieron los primeros moradores de una Ronda cristiana inserta en la Corona de Castilla fue una sencilla construcción que conservaba el lugar y, probablemente, parte de la forma de la antigua mezquita dentro de una estética claramente gótica. Pero, imprevisiblemente, unas circunstancias totalmente adversas impidieron a los rondeños el disfrute de un espacio sagrado estable donde poder realizar sus plegarias a la divinidad protectora, pues, transcurridos apenas cien años de la conquista y sin haberse colmatado su erección, comenzó una larga serie de fenómenos naturales que se extenderían hasta finales del siglo XVII, suponiendo un capítulo importante de la historia de Ronda durante el Antiguo Régimen.

\section{UN ACECHO CONTINUO DE CALAMIDADES: LUCES Y SOMBRAS DE UN LARGO PROCESO CONSTRUCTIVO (SS. XVI-XVII)}

A pesar de que las noticias arquitectónicas que nos permiten hablar de la iglesia de la Encarnación como tal se retrotraen a 1508, desde los inicios de la centuria encontramos datos que inciden claramente en su existencia y en su papel en los quehaceres espirituales que se iban fraguando. Ya, las ordenanzas de la cofradía de la Caridad de la ciudad, fechadas en 1500, señalan la "yglesia de santa Maria" como templo en el que celebrar, al 
menos, unas de las tres fiestas anuales de la corporación, lo que evidencia la importancia que, irremediablemente, cobraba como lugar de culto principal $^{8}$. Ya en 1501 sabemos de la necesidad de campanas para la iglesia 9. El paisaje de la reconquista debía afirmar con énfasis su fe cristiana, sobre todo en unas tierras donde la cuestión mudéjar y después morisca se dejará sentir con fuerza. Por tanto, la progresiva cristianización de la sociedad por medio de diferentes elementos ineludibles se hacía necesaria. La iglesia constituía, por excelencia, el culmen de los mismos, y a esta se debía añadir, acorde con su función social, el instrumento de llamada a la oración. Las campanas cumplirían a partir de este momento dicho papel. No obstante, y como veremos que resulta una constante durante la historia de la iglesia, la falta de rentas hacía imposible su compra, informándose de tal situación a los reyes, suplicándoles sufragaran tal adquisición ${ }^{10}$.

$\mathrm{Si}$ nos centramos en pesquisas estrictamente materiales -aunque la presencia de tal espacio sagrado en la cotidianidad urbana es más que palpable desde el quinientos-, las primeras referencias acerca del proceso constructivo se remontan a 1508. En esa coyuntura, el modesto templo cristiano, que con toda probabilidad estaba inconcluso, se postuló pequeño e insuficiente para acoger a los devotos de una Ronda reconquistada, la cual experimentó un importante crecimiento poblacional a comienzos del siglo XVI: "siendo que la yglesia mayor de la dicha çibdad que se dise Santa Maria de la Encarnaçion dis que es muy pequenna e que esta fecha pobremente e que dicha çibdad se puebla e os de cada dia mayor..."11.

Ante esta situación, se proyectó un ensanche del edificio, que debió materializarse en una ampliación de las naves aún en construcción ${ }^{12}$. En efecto, sabemos que en 1520 ya estaban construidas, no sin un gran esfuerzo,

8. Archivo General de Simancas (AGS), Registro General del Sello (RGS), leg. 150002, 1, "Confirmación de las ordenanzas de la cofradía de la Caridad de Ronda, insertas". El libro de Repartimiento de Ronda recogía seis colaciones tras la Reconquista de la ciudad: la colación de la Encarnación, del Santi Espíritus, de Santiago, de Sant Juan Bautista, de Sant Juan Evangelista, y de Santi Stevan. De todas ellas, la de la Encarnación se alzó como hegemónica. M. Acién Almansa (1977), 9.

9. AGS, Cámara de Castilla (CCA), Libro General de Cédulas (CED), 5, 333,3, "Información sobre la necesidad de campanas para la iglesia de Ronda"; AGS, CCA, CED, 5, 286, 2, "Necesidad de campanas en las iglesias de Ronda".

10. AGS, CCA, CED, 5, 333,3, "Información sobre la necesidad...".

11. Archivo de la Real Maestranza de Caballería de Ronda (ARMCR), fondo Archivo Rafael Aguilera, legajo 32 eclesiástico, documento 4593.

12. Ibidem. 
dos naves ${ }^{13}$. Para este menester fue preciso empeñar varios objetos de plata y la cesión de rentas por parte del Hospital Real, que en estos momentos contaba con suficientes recursos, a diferencia de las mermadas arcas de la iglesia ${ }^{14}$. No obstante, la fábrica distaba bastante de estar conclusa, pues la labor de construcción de una tercera nave se antojaba difícil en la tesitura de las escasas rentas de las que gozaba el templo, y por el contrario, los acuciantes gastos presentados. Sin embargo, el colofón de la iglesia se hacía, cuanto menos, necesario, máxime ante la situación presente: "en esta çibdad ay solamente una yglesia que se dize de nuestra sennora de la Encarnaçion que es la principal yglesia de donde se dan los sacramentos a toda la çibdad e a donde todos van a oir missa..."15. Esta afirmación, ciertamente, nos delata que el funcionamiento del resto de parroquias locales no había cuajado de forma plena en la década de los años veinte, concediendo todo el protagonismo a la iglesia mayor, que, a todas luces, no podía soportar. La construcción siguió adelante y, al parecer, en 1534, las obras habían avanzado considerablemente ${ }^{16}$.

Pero tempranamente, en el mismo siglo XVI, los efectos de diversas calamidades de índole natural empezaron a dejar señales en el templo. La torre mudéjar que cumplía la función de campanario sería la primera parte de la iglesia en verse afectada de forma reiterada. Según la historiografía local el día del Corpus del año de 1523, un rayo impactó en la primitiva torre de la iglesia ${ }^{17}$. El segundo de los rayos que afectó a la torre mudéjar está mejor

13. AGS, CCA, Memoriales 138-34, 1520, obras. Documento citado en A. Miró Domínguez (1987), 242.

14. El Hospital Real de Ronda fue fundado por los Reyes Católicos tras la conquista de Ronda para asistir a los pobres de la ciudad. En 1683 fue entregado a la orden Hospitalaria de San Juan de Dios, pasando a recibir el dicho nombre. De Pineda (1717), 289-290.

15. AGS, CCA, Memoriales 138-34, 1520, obras.

16. L. Torres Balbás (1944), 467.

17. J. A. Campos Naranjo, manuscrito inédito, fol. 26 r. Este autor nos indica: "entren en esta cuenta los dos rayos que hirieron su Yglecia Mayor, el uno habrá más de 60 años, que partió su torre, que después se labró la hermonsa y pulida que oy tiene, día octavo del Corpus, estando gran concurzo de gente en la Yglecia, rompió su techo y se profundizó junto al Sagrario asombró que movió y dio motivo a la reconsiliasión de dos familias opuestas; el otro siendo corregidor Dn Juan de Salinas, Cavallero del Orden de Calatrava, día de Pasqua de Resurreción, estando oyendo misa $\mathrm{D}^{\mathrm{a}}$ María de Frías, Corregidora, en el Altar de las Reliquias inmediata a la puerta de la Torre, vajó y salió por ella el rayo, quemándole el manto, y se profundó sin más daño que pudiera hacer por la mucha gente que en la Yglecia havia”. Siglos más tarde Moreti matizará en una cita explicativa este hecho de la siguiente forma: "Una muestra de los trabajos 
documentado. Varios cronistas describen el episodio en sus textos y, lo que es más importante, uno de ellos, Macario Fariñas del Corral, presenció la destrucción y reconstrucción de tan insigne obra: "Labrose apriesa la yglesia mayor donde estava la mesquita mayor e hízole una torre mui hermosa que derribó un rayo el año de 1605 y se reedifico mejor que antes"18.

Sin embargo, si en dos ocasiones la torre se dañó, en mayor o menor medida, los verdaderos estragos en la obra se producirían más tardíamente. En 1580, coincidiendo con la expansión por la geografía andaluza de una epidemia de peste bubónica se produce, según Moreti, la primera gran destrucción de la fábrica de la iglesia provocada por un terremoto:

Mas como á consecuencia del terremoto que sufrió esta ciudad en 1580 se desplomó toda la parte N. de tan bonita obra, al levantarla surgió el pensamiento de su ensanche, á lo cual se brindó gustoso el vecindario y cuerpo Municipal allegando fondos suficientes. Ignórase por completo el arquitecto á quien se encargase la obra proyectada y la época esasta en que se emprendiera la continuación de la magnífica obra y suntosa fábrica que enlaza constituye nuestra grandiosa iglesia ${ }^{19}$.

Corresponde precisar que la documentación conservada - por lo demás escasa-, no refleja ningún temblor de tierra en el citado año de 1580. Sí se recoge una sacudida un año después, pero con un alcance limitado a la urbe malacitana ${ }^{20}$. Tales circunstancias no nos permiten analizar el supuesto terremoto de 1580, relegando su veracidad o falsedad a la historiografía local. Moreti, único autor que recoge en sus páginas tal catástrofe, llega a contradecir su propia tesis en varias ocasiones, afirmando que fue el terremoto de 1680 el causante de la destrucción de la iglesia ${ }^{21}$. Toda esta explicación la achaca al contenido de una lápida, cuyas posibles lecturas condicionan, en gran medida, la cronología del terremoto. Dicha lápida, situada en el lado derecho accediendo a la iglesia por la puerta de Levante,

arquitectónicos es la preciosa torre de nuestra iglesia de Sta. María de la Encarnación, la cual habría sido destruida por un rayo en 1523, día del Cuerpo de Cristo y se reedificó en los años siguientes en la forma que hoy conserva". J. J. Moreti (1993), 492.

18. M. Fariñas del Corral (2014), 195.

19. J. J. Moreti (1993), 716.

20. C. García de la Leña (1789), 23; F. Guillén Robles (1985), 472. García de la Leña sitúa el terremoto el 18 junio de 1581, mientras que Guillén Robles lo hace justo un mes más tarde, el 18 de julio.

21. J. J. Moreti (1993), 528, 547-549. 


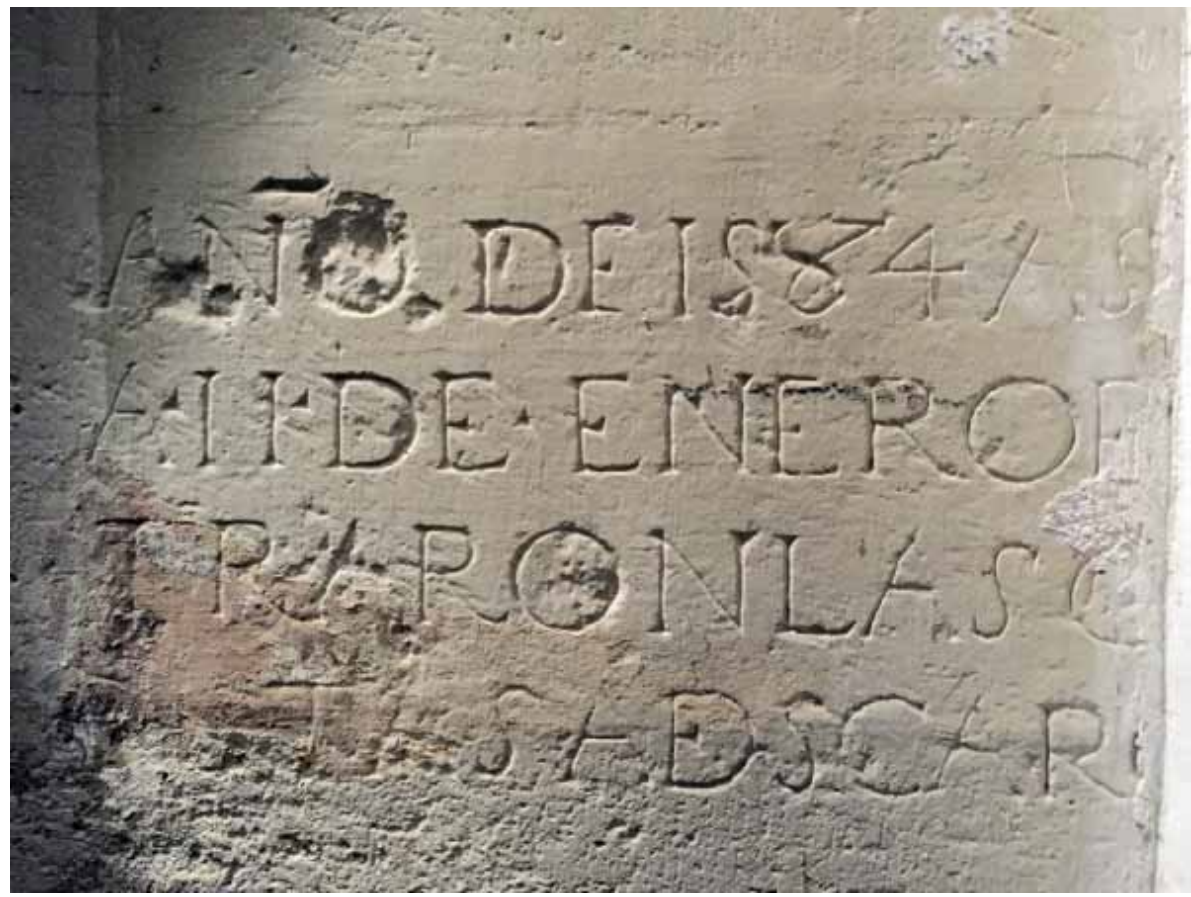

Figura 1. Lápida referenciada en el texto (Fuente: fotografía propia del autor).

junto al callejón de los Tramposos, cuenta con una inscripción epigráfica en la que podemos leer: "ANNO DE $1684 \mathrm{AS} / \mathrm{A} 11$ DE ENERO E/ (n) TRARON LAS CA/ (rre) TAS A DESCAR (¿gar?)".

Este epígrafe ha sido motivo de confusión dada la imprecisión técnica en uno de los números del año labrado que dificulta discernir la grafía, pero que resulta de importancia capital, pues constata el inicio de las obras. Moreti hace una lectura de este sillar interpretando que la cronología plasmada resulta ser el año de 1584. A partir de este hecho desarrolla la hipótesis de un terremoto en 1580. Por el contrario, la rotundidad de esta tesis contrasta con sus dudas. De hecho, se inclina hacia la posibilidad de una destrucción y reconstrucción posterior causada por el terremoto de 1680 , cuyas consecuencias se dejaron sentir por toda la actual provincia de Málaga ${ }^{22}$.

22. Ibidem, 528-529. En dos pasajes queda patente dicha idea que remiten el suceso con una cronología posterior en alusión directa al terremoto de 1680: "Por mas que así lo dice la tradición y parece que lo acredita dicho escrito [en referencia a la lápida] el 
No sería hasta que Amador de los Ríos, ya en el siglo XX, recuperara la idea planteada por Moreti, y basándose, a su juicio, en unas razones paleográficas, argumentó que la tradicional lectura del sillar era errónea, pareciendo un 5 lo que en realidad era un 6 , tratándose, por tanto, del año $1684^{23}$. De esta forma, los indicios parecen constatar que fue el terremoto de 1680 el causante de la gran tragedia. Unos años más tarde, en un lugar visible al pueblo, como es una de las puertas de acceso al templo, quedaría grabado en piedra ad perpetuam el acto de reanudación de las obras tras el gran terremoto.

Con todo, no es esta la única polémica encuadrada aún en el siglo XVI, pues, igualmente, las crónicas locales recogen que en 1580 una tormenta encapotó el cielo, descargando con furia agua y rayos ${ }^{24}$. Uno de esos rayos cayó en la iglesia mayor destruyendo "el lienzo norte de la iglesia"25. Sin tener constancia documental en este asunto que nos permita obtener firmes conclusiones, es posible que algún daño sufriera el templo -o precisara reformas o ampliaciones-, cuando el obispado de Málaga adjudicaba el sueldo de maestro mayor para la "iglesia de Ronda" a Pedro Díaz de Palacio en octubre de $1598^{26}$. A ello sumamos que, en 1640, el obispo de Málaga durante su vista a Ronda destinó rentas y fondos para la continuación de las obras de la iglesia mayor ${ }^{27}$.

terremoto que destruyó la iglesia debió ser el de 1681, pero no hay datos seguros". "Solo dire que á mi juicio, por más que no hay datos sobre ello, y antes parece que prueban lo contrario, la grande obra de Sta. María de la Encarnación, es decir, la iglesia nueva debió empezarse en 1684, siendo el primero de los edificios que se construyeron en esta época". J. J. Moreti (1993), 549.

23. J. AMAdor de los Ríos, (1907), 385.

24. J. J. Moreti (1993), 527. "Y todavía no habían salido de tan desgarradora situación, cuando un nuevo contratiempo vino á afligir el vecindario. Serían las cuatro de la tarde del 18 de Junio: el cielo empezó a encapotarse y á poco algunos relámpagos hicieron recelar la aproximación de una tormenta: y en efecto, pausados relámpagos seguidos de algunos truenos se hicieron sentir; pero á poco eran tan continuados y tan fuertes que el pueblo todo se consternó (...). Y no fue solo la muralla lo que cayó en aquel momento, sino que gran parte de la iglesia fue destruida por un rayo que derribó el lienzo de pared que caía al Norte".

25. F. LozAno Gutiérrez (2005), 171: "El 18 de junio del mismo año, descargó sobre la afligida ciudad una terrible tempestad donde no faltaron horrísonos truenos, relámpagos a milares, huracán desenfrenado, temblores de tierra y frecuentes tormentas eléctricas que dieron por resultado el hundimiento casas, el desplome de la muralla en el segundo recinto por el E., y la destrucción por un rayo del lienzo N., de la Iglesia de S cuyo edificio no parecía sino predestinado a atraerse cuantas chispas de fuego brotaban de las nubes..."

26. A. LloRdÉn (1962), 57.

27. J. J. Moreti (1993), 718.

(C) Baetica. Estudios Historia Moderna y Contemporánea, 38, 2018, 47-77. Facultad de Filosofía y Letras, Universidad de Málaga. Departamento de Historia Moderna y Contemporánea 
Dejando atrás las catástrofes del quinientos, sería en el llamado "siglo maldito" -adjetivo que igualmente refleja la fortuna de la iglesia rondeñacuando varias pandemias de peste junto con otras catástrofes naturales incidieron directa o indirectamente al templo. En suma, el registro documental para estos casos se presenta más rico y favorece un análisis más completo.

A finales de la década de los setenta se inició una nueva epidemia de peste negra, conocida como cartagenera, por ser este el primer puerto afectado, si bien parece que el contagio de las tierras malacitanas se produjo por el foco latente del Norte de África ${ }^{28}$. La plaga llegaría a la ciudad de Málaga en el verano de 1678 para extenderse por el interior de la provincia y ser, a comienzos del 1679, una dura situación a combatir en Ronda ${ }^{29}$. Un impreso conservado en la Biblioteca Nacional y pregonado el 6 de julio de 1679 informaba de la prohibición del tráfico y la comunicación entre diversos lugares contagiados del reino de Granada, entre los que hace aparición la ciudad de Ronda ${ }^{30}$.

La intensidad de la plaga dejó secuelas en toda el vecindario y la escasez de agua provocó un prolífico contagio entre la población que se vería considerablemente mermada tras este mortífero suceso ${ }^{31}$. Además, apenas unas décadas antes, en 1649, Ronda se había visto igualmente afectada por otra peste bubónica ${ }^{32}$. Tras este suceso, la urbe tardaría unos años en recuperarse, debido al considerable descenso de efectivos humanos -con todo lo que ello conllevaba-, y a la incidencia de la plaga en la economía local, pues esta hizo necesario el gasto de importantes cantidades de dinero en asistencia hospitalaria, enterramientos, alimentos, limpieza, etc. De ahí la miseria de la hacienda municipal, hecho que tendrá que sobrellevar el

28. M. LEÓN VEGAS (2007), 160.

29. Archives Nationales (Francia), "Correspondance des consuls de France à Cadix", $\mathrm{AE} / \mathrm{B} / \mathrm{I} / 211-\mathrm{AE} / \mathrm{B} / \mathrm{I} / 300$ - Fol. 269-269v. El documento referenciado puede consultarse en el siguiente enlace: https://www.siv.archiesnationales.culture.gouv.fr/siv/rechercheconsultation/consultation/ir/consultationIR.action?irId=FRAN_IR_053989\&details=fals e\&gotoArchivesNums $=$ false \&udId=root\&auSeinIR $=$ true \& formCaller=GENERALISTE (09/2018). La presencia de la peste en Ronda queda registrada hasta finales de 1679, cuando ante la inminente apertura del puerto de Málaga, el cónsul francés en Cádiz informaba de los núcleos aún infectados al ministro galo Jean Baptiste Colbert.

30. Biblioteca Nacional de España, Porcones/1326/1: "Para la Guarda del contagio de las Ciudades de Granada, Motril, Antequera, Ronda, Malaga y Velez-Malaga, se ha de obseruar... [que se sigan las indicaciones para evitar la propagación de la peste]". Fernández de Noriega, Miguel (redactor), [s. n.], [s. 1.], [1679?]

31. M. Reder Gadow (2006), 485.

32. M. Fariñas del Corral (2014), 134-135.

(C) Baetica. Estudios Historia Moderna y Contemporánea, 38, 2018, 47-77.

Facultad de Filosofia y Letras, Universidad de Málaga. Departamento de Historia Moderna y Contemporánea 
concejo rondeño durante años, con unas consecuencias directas sobre la iglesia mayor.

Todas estas circunstancias no hicieron más que agravar la difícil situación que vivía Ronda a finales del siglo XVII, a la que debemos sumar el devastador terremoto que se desencadenó de forma casi paralela al fin de la última peste. El 9 de octubre de 1680 una profunda sacudida se dejó sentir por el sur peninsular, con especial hincapié en Málaga ${ }^{33}$. El epicentro se situó cerca de la capital causando estragos en la misma, así como en las poblaciones de su entorno, pero llegando a llegando a sentirse en localidades más alejadas como Antequera o Ronda ${ }^{34}$.

Una de las múltiples víctimas de este temblor de tierra sería la iglesia mayor de Ronda que, ya con varios altercados en su pasado reciente, había servido como el principal templo de la ciudad para la celebración de los oficios religiosos. Además, tenemos constancia de su plena integración en el urbanismo rondeño como un elemento embutido en su trama y rodeado al completo por casas particulares que la flanqueaban casi en su integridad ${ }^{35}$. Todo ello no deja de ser una muestra de la vitalidad de la actividad urbanística, cuya potencia se proyectaba ya desde el siglo XVI, y en aumento durante toda la Edad Moderna, en el barrio del Mercadillo ${ }^{36}$.

Así, el terremoto vino a afectar a la ciudad con gran daño en el pleno corazón de la misma. Moreti rememora el temblor de la siguiente forma:

Era el mes de octubre y el dia nueve de él, cuando una sorda sacudida acompañada de terribles y continuados aguaceros, dieron en tierra con mucha obra de nuestra iglesia mayor. La parte Norte de ella quedo descubierta teniendo inmediatamente que proceder á desnudarla de cuanto contenía temiendose un desplome ${ }^{37}$.

33. A. Rubia Lozano (2017), 157.

34. P. Pereiro Barbero (1985), 34-39; B. Vincent, (1986), 27-34. Otro interesante estudio sobre el sismo y su impacto en la producción documental lo encontramos en M. RUEDA Ramírez y M. Fernández Chávez (2008), 581-604.

35. Documento no catalogado custodiado en la biblioteca de la iglesia de Santa María la Mayor de Ronda, fol. 33 r. Se trata de un libro de contabilidad eclesiástica que podemos datar en la segunda mitad del siglo XVIII. Recoge información de una temporalidad dilatada -desde comienzos del siglo XVI hasta bien entrado el XVIII- donde aflora la cuestión económica, en especial los pagos de las misas por el alma de difuntos, ya sea de particulares, instituciones colectivas o cofradías.

36. A. Miró Domínguez, (1987), 141-145.

37. J. J. Moreti (1993), 54. 
El terremoto había destruido el mayor templo de Ronda e inhabilitado, por tanto, su función principal: servir como lugar santo para la celebración de los actos religiosos ${ }^{38}$. La sociedad contemporánea a los hechos debió vivir este suceso con una gran conmoción, no solo por la potencia del temblor presenciado, sino por el instante en que se produjo. La situación local previa era especialmente delicada, aún convaleciente de la peste de 1649, la peor epidemia pestilente acaecida. Además, no era la primera vez que un desastre natural -bien terremotos, rayos o tormentas- afectaba a la iglesia mayor, dado que ya se había visto perjudicada en varias ocasiones.

Si la sociedad del Antiguo Régimen ya contó con dificultades inherentes para la subsistencia, la presencia continuada de vicisitudes que acrecentaban la dura vida de las gentes de los tiempos modernos no hacía sino desestabilizar multidireccionalmente los ritmos cotidianos de aquellos. Bien es sabido que la catástrofe hace aflorar en el pueblo un sentimiento de miedo que desemboca en un terror derivado de lo extraordinario de la situación ${ }^{39}$. En este caso, el impacto físico y humano de las calamidades no excluyó el mental e ideológico, pues la afección directa del principal templo local $\mathrm{y}$, con ello, la institución eclesiástica, piedra angular de la sociedad, se alzaría en un suceso indeleble en el recuerdo del común.

Los devotos cristianos veían sin cesar cómo su Dios castigaba con ira los pecados cometidos por los hombres. Debemos tener en cuenta que los terremotos, con un transcurso temporal bastante reducido, engendraban secuelas que se demoraban años tras el suceso $^{40}$. En este caso, supuso, por sus circunstancias y características, un punto y aparte en estas calamidades que se antojaban interminables. Si nos referimos al ejemplo de

38. A pesar de que son varias las crónicas que documentan los daños sufridos por la iglesia a raíz del temblor de 1680 , e igualmente avalados por el proceso de reconstrucción posterior, exhaustivamente documentado, no debemos dejar de mencionar a Campos Naranjo, médico municipal de Ronda, quien escribió en 1683 su Epitome Historial de Ronda. Al ocuparse de las parroquia locales indicaba: "Santa Maria Yglecia Mayor que por lo demolido del terremoto del dia 9 de octubre del año pasado de 1681, se paso su administración al Hospital Real, como el Cavildo Eclesiástico de Señores Beneficiados al Espiritu Santo...”. Su contemporaneidad a los hechos y la redacción y publicación de la obra que nos ha legado tan solo tres años tras la catástrofe nos hace pensar que su retraso en la fecha del desastre -1681- se debe a un error de redacción y/o transmisión posterior. Por lo demás no deja de ser otro firme respaldo documental de los efectos del temblor en tierras rondeñas. J. A. Campos Naranjo, manuscrito inédito, fol. $18 \mathrm{r}$.

39. A. Alberola Romá (2012), 56.

40. A. García Torres (2018), 797. 
Málaga, con una situación similar, tras el temblor afloró una "literatura de explicaciones y remedios ante la desgracia natural", con la que se intentaba dar una respuesta al pueblo de lo sucedido y actitudes morales para el futuro ${ }^{41}$.

La destrucción de una iglesia debió postularse como un hecho difícil de esclarecer ante las gentes en esta lectura de castigo divino, dado que el afectado era el propio templo de Dios, desde donde habrían de partir las oraciones para obtener el perdón y evitar situaciones similares. Si bien las catástrofes eran voluntad de Dios, las motivaciones para estas eran puramente terrenales: el mal obrar de los hombres y, por ello, las reacciones piadosas ante la calamidad, tal y como ocurrió en el caso malagueño, no se dejarían esperar ${ }^{42}$. Ya fray Alonso de Santo Tomás, obispo de Málaga, en la Carta Pastoral, hacía una analogía del estado de la capital de su diócesis con ejemplos bíblicos y ante situaciones como la presentada recurrió a las explicaciones de los profetas: estas destrucciones tenían como fin fortalecer al pueblo y reformar las posturas morales de la sociedad ${ }^{43}$.

Con todo, los desastres conllevaron una repercusión económica de profundo calado: las arcas de la ciudad estaban exhaustas y en tales condiciones resultaba imposible emprender la costosa reparación del templo. En 1683 el concejo rondeño, amparándose en la pésima situación de su hacienda tras estas calamidades, pidió a la corona una prórroga en el pago de las deudas contraídas ${ }^{44}$.

No había pasado un año del terremoto, en mayo de 1681, cuando la reconstrucción de la iglesia mayor empezaba a formar parte de los puntos a tratar por el cabildo de Señores Beneficiados de las fábricas de la ciudad de Ronda. La sinopsis general de la situación del templo y sus repercusiones más inmediatas quedaban claramente recogidas:

41. M. L. López-Guadalupe Muñoz, y J. García Bernal (2010), 339.

42. A. Alberola Romá (2012), 70; F. Fernández Basurte (1992), 216. En la ciudad de Ronda, la falta de documentación para el terremoto de 1680 nos impide un análisis más completo del fervor religioso ante la catástrofe, como bien queda atestiguado para el temblor de 1762. En tal situación, la ausencia de daños graves en la urbe fue agradecida a la divinidad por medio de la celebración de una fiesta el Día de Todos los Santos con la reseñable presencia de cera -elemento bastante común en las ceremonias religiosas-y decenas de cohetes, que reincide en la connotación positiva de la festividad celebrada. Vide: Archivo Histórico Municipal de Ronda (AHMR), legajo 013-006, "Fiesta terremoto".

43. Ibidem.

44. El citado hecho se recoge en un legajo del AHMR, estudiado y transcrito en P. SIERRA DE Cózar (2009), 10. 
Parece que en cavildo celebrado por esta ziudad en 31 de mayo de 1681 años se confirio largamente sobre la rredificacion de la dicha yglesia que se hallaba arruinada con sumo desconsuelo por estar el Santistimo Sacramento en ylgesias estrechas y las rreliquias e ymagenes rreparttidas en ellas y aun algunas en casas particulares y a ttan grave general desconsuelo se llegaba hallare los señores beneficiados sin yglesia propia donde asistir a sus obligaciones del culto divino padeciendo la incommodidad de yr a la parrochia del Spiritu Santto a selebrar los divinos oficios miu distante para sugettos delicados por su edad y esttudios quebrattados y abiendose tenido diferenttes juntas y conferencias entre los sennores beneficiados y cavalleros reguidores sobre el referido asumpto ${ }^{45}$.

El malestar del pueblo era notable. Ante la falta del templo principal de la ciudad, las funciones religiosas que desempeñaba fueron asumidas, en la medida de sus posibilidades, por la iglesia del Espíritu Santo junto a otras parroquias de menor categoría. Dicho templo tenía una evolución, en cierto modo, similar a la iglesia mayor, pues había sido mezquita menor de la ciudad durante la dominación musulmana y, tras ella, fue transformada al rito cristiano. Tuvo un funcionamiento paralelo a la iglesia de la Encarnación como el segundo templo de mayor importancia en la ciudad ${ }^{46}$, y no parece que se viera afectado por el terremoto de $1680^{47}$.

\section{EL CAMINO HACIA UNA LENTA RECONSTRUCCIÓN: LA DIFÍCIL FINANCIACIÓN DEL TEMPLO}

A partir de 1681 se iniciaron las conversaciones y las reuniones del cabildo con un objetivo claro: la búsqueda de fondos económicos con los que sufragar los gastos de reconstrucción. La primera mirada se dirigió hacia los propios y las rentas de la localidad, que, en principio, podían contribuir en mayor o menor medida, pero la epidemia de peste de 1678-79 hizo in-

45. ARMCR, Fondo privado familia Clavero, leg. 197-3, s. f. "Certificación del escribano Diego Romero, sobre varias acuerdos de las sesiones del Cabildo de los años 1681 al 1684 ante Alonso Matías de Sierra, escribano. Sobre las obras de la Iglesia Mayor de Ronda".

46. En pleno siglo XVII, la ciudad contaba con tres barrios claramente diferenciados: la "ciudad" con la colación de Santa María de la Encarnación; el Mercadillo con la iglesia de Santa Cecilia y la cada vez más importante iglesia-hospital del Socorro, si bien, aún sin la categoría de parroquia; y, finalmente, el barrio de San Francisco con la iglesia del Espíritu Santo. Para más información urbanística vide A. Miró Domínguez (1987), 37-65.

47. Campos Naranjo nos la describe como "segunda parroquia templo de mucha capasidad, de admirable y fortísima fábrica...". Pudo ser esta fortaleza la que debió limitar y/o evitar los efectos del terremoto. J. A. Campos Naranjo, manuscrito inédito, fol. $18 \mathrm{r}$. 
viable esta contribución al quedar retrasada la recaudación impositiva ${ }^{48}$. No obstante, se acordó "aplicar a fin tan premio las sobras que hubiera en los propios..."49. Ante tal situación quedaban dos vías por explorar: los arbitrios locales y el diezmo eclesiástico, que fueron exhaustivamente estudiados.

En lo que respecta a los arbitrios, en 1681, el citado capítulo eclesiástico se encargó de poner al corriente al rey de la delicada situación local y de los daños producidos en el templo para que concediese a la población los arbitrios necesarios, y poder así reunir fondos para las obras ${ }^{50}$. Dos años más tarde, en 1683, una real provisión del Consejo de Castilla pedía al concejo rondeño una detallada información acerca de los arbitrios y su situación, dado que el disfrute de los mismos, para diferentes donativos y servicios, antecedía a la década de los ochenta.

La cuestión de los arbitrios quedó aparcada hasta un año más tarde, cuando se conoció la concesión de la toma de arbitrios para la obra del templo. El impuesto se destinaría a la fábrica y se concretaría finalmente en el $1 \%$ de las carnes y ganados vendidos en las carnicerías de la ciudad y de cada cuarto de libra de jabón; un 3\% de las mercaderías vendidas en la feria de mayo y, finalmente, el arrendamiento de caballos y de la fuente de la Arena ${ }^{51}$. Todo ello debía sumar una contribución anual de dos mil ducados. La noticia fue recibida con gran consuelo en la ciudad y se pusieron en marcha los mecanismos precisos para su cobro y administración. La reparación del santo lugar estaba, aparentemente, un paso más cerca.

Por otra parte, no podemos olvidar la vía tributaria eclesiástica: el diezmo. El cabildo, deseoso de poder alzar de nuevo el inmueble, desde el primer momento no se contentó solo con la solicitud real de arbitrios, sino que también instó la ayuda de la Iglesia. De facto, la intención era rehabilitar el templo, posibilitar los oficios y la religiosidad del pueblo. La

48. ARMCR, Fondo privado familia Clavero, leg. 197-3, s. f. “Certificación del escribano Diego Romero, sobre varios acuerdos...".

49. ARMCR, Fondo privado familia Clavero, leg. 196-23, s. f. "Borradores y copia del memorial sobre la mala administración de los arbitrios que debían estar dedicados a la fábrica de la Iglesia Mayor y a la traída de aguas del Barrio del Mercadillo desde el día 2 de julio de 1684 ".

50. ARMCR, Fondo privado familia Clavero, leg. 197-3, s. f. "Certificación del escribano Diego Romero, sobre varios acuerdos...".

51. Ibidem. Como se desprende del mismo documento, estas cláusulas se mantuvieron intactas hasta 1722. Respecto a la problemática del agua en Ronda y su abastecimiento, esta ha sido ampliamente estudiada en P. Sierra De Cózar, y J. E. Sierra Velasco (2011), 37-67; A. Miró Domínguez y R. Camacho Martínez (1994), 109-128. 
instancia a la que se recurrió fue al obispado de Málaga -del que dependía la vicaría de Ronda- y, con él, a su titular, fray Alonso de Santo Tomás, a quien se comunicó la intención, previamente anunciada por parte del rey y del Consejo de Castilla, de "hacer repartimientos entre las personas que gozaban diezmos eclesiásticos y que se aplique a dicha obra" 52 .

Dicho atrevimiento no fue bien acogido por el prelado. Su respuesta fue firme y contundente: una iglesia de patronato real debía ser preocupación del rey. Además, el obispo recriminaba la petición de repartimientos de los diezmos instigada por el rey, pues, desde la conquista del emirato nazarí, la Corona recibía ya parte de esos diezmos. Los Reyes Católicos consiguieron por medio de la intersección del conde de Tendilla, la concesión de bulas apostólicas por parte de Inocencio VIII y de su sucesor Alejandro VI, que se concretaron en la asignación de los diezmos que pagaban los musulmanes granadinos -aunque el $50 \%$ de los mismos irá a parar a la diócesis- y en las tercias reales ${ }^{53}$. Estas, dos partes de nueve, constituían la fracción realenga de los diezmos pagados por los repobladores cristianos, y son a las que alude el obispo malagueño en su carta al cabildo rondeño.

Así, el patronato regio, que incluye, entre sus atribuciones, el mantenimiento en sí de las fábricas, constituye el argumento esgrimido por fray Alonso de Santo Tomás para rechazar la posibilidad de realizar repartimiento alguno sobre los diezmos eclesiásticos para las obras de la iglesia. Tal apoyo debía provenir de la monarquía, como ya se acordó con el papado en el siglo XVI. La cuestión, como vemos, no estuvo exenta de controversia. Se trataba de un choque entre la autoridad real y la eclesiástica, encarnada en la figura del prelado, dado que estaba en juego una cuestión pecuniaria.

Con toda la ardiente polémica, se hizo liquidación del valor de las rentas decimales de la ciudad y su vicaría con la intención de aplicar a la obra un noveno de los diezmos en "el valor de los maravedíes y granos que se recogían en las sillas de la ciudad" ${ }^{54}$. La cesión de los diezmos no estaba clara, dado los intereses contrapuestos de Monarquía e Iglesia en este asunto, y no sería hasta dos años más tarde cuando la situación se aclarase.

La misma cuestión económica que situaba en polos opuestos al monarca y al obispo, saltó al ámbito local de un modo muy similar. En 1684 ante

52. ARMCR, Fondo privado familia Clavero, leg. 197-3, s. f. "Certificación del escribano Diego Romero, sobre varios acuerdos...".

53. J. E. López De Coca Castañer (1977), 149-150.

54. ARMCR, Fondo privado familia Clavero, leg-197-3, s. f. "Certificación del escribano Diego Romero, sobre varios acuerdos...". 
la posibilidad de volver a plantear el repartimiento de los diezmos, don Diego de Espinosa, beneficiado y presidente de la iglesia de la Encarnación argumentó la imposibilidad de tal opción con la célebre expresión: "era vigor pretender reedificar un templo muerto con el atraso y destrucción de los templos vivos" ${ }^{\prime 5}$. Una hipotética desviación de los beneficios de las parroquias de Ronda en favor de la iglesia mayor resucitaría el templo, pero con la consiguiente muerte de las demás parroquias por la escasez de fondos con los que subsistir. Por tanto, dado que la cantidad de rentas manejadas por los templos en funcionamiento difícilmente permitía el sustento de los mismos, la cesión de rentas a la iglesia de la Encarnación supondría un mal mayor. La cuestión de los diezmos quedaba zanjada: su aportación sería nula. Los arbitrios quedaban como único apoyo para las obras.

Resulta curioso - pero no extraño por ser un fenómeno muy común en el devenir histórico-, como la variable dineraria ponía en jaque a todas las facciones. Los escasos recursos eran muy valiosos en tiempos tan convulsos y difíciles, y nadie quería desprenderse de bien tan preciado. Ni la habilitación de un templo -con la importancia de la institución eclesiástica y del sentimiento religioso en el seno del pueblo-, suponía un tema tan trascendental para la aportación de caudal financiero: tanto la Iglesia como la Corona-quien solo cedió arbitrios-, se evadieron en la medida de lo posible. Se trataba de una cuestión que concernía al pueblo rondeño, quien sufría la ausencia de la iglesia y, en última instancia, el que asumiría su reconstrucción. De este modo, ante la falta de unos apoyos firmes que sustentaran económicamente el asunto, fue el esfuerzo colectivo de la urbe y de sus conciudadanos quienes, a través de sus impuestos a lo largo de medio siglo, hicieron posible ver de nuevo en pie la iglesia de la Encarnación en el centro de la ciudad del tajo.

A pesar de la fuerza y voluntad del pueblo, la pobreza -en términos generales, pero aquí referida a lo fiscal- era un problema cotidiano con el que tenían que lidiar. El continuo pago de arbitrios durante un periodo de diez años -que fue el concedido inicialmente- no fue suficiente para culminar las obras. La prórroga en el uso de los arbitrios por parte de la Corona se convirtió en una constante durante el final del siglo XVII y el primer cuarto del XVIII. La última cesión data de 1722 por tiempo de seis $a_{n}{ }^{56}{ }^{56}$. De estos datos se evidencia la lentitud del proceso constructivo.

55. Ibidem.

56. ARMCR, Fondo privado familia Clavero, leg. 196-23, s. f. "Borradores y copia del memorial sobre la mala administración de los arbitrios...”. 


\section{LAS OBRAS EN EL SIGLO XVIII Y LA CONCLUSIÓN DE LA IGLESIA: ENTRE LA ESPERANZA Y LA DESESPERACIÓN}

En 1684 comenzaron las obras en el cuerpo de la iglesia y en la capilla mayor a expensas de los arbitrios. La intervención en la parte central de la fábrica no debió ser tan dilatada como la ejecutada en la cabecera. De hecho, una vez "fenesido el cuerpo de la yglesia" se colocaron las imágenes, el Santísimo Sacramento y se pasó a celebrar culto ${ }^{57}$. El templo pudo así retomar su actividad, si bien no en su integridad, pues el espacio disponible quedaba restringido a la referida parte habilitada y, con ello, el número de fieles que podían asistir a los oficios: "presisandose selebrar las fiestas en la cortedad de la yglesia vieja donde no podía por su estrechez ser mucho el concurso"s8.

La gestión de los arbitrios no debió llevarse a cabo con gran acierto, pues poco después se recriminaba el mal uso realizado de los mismos. En 1700, por iniciativa de Mathias Luzon, presbítero y mayordomo de fábricas, y con el apoyo de los señores beneficiados y del corregidor Sancho de Castro y Lossada, se acordó sacar las obras de la iglesia a pregón público ${ }^{59}$. Así, a comienzos del siglo XVIII, los avances no debieron ser muy considerables. Nos consta que en el momento del concurso, la iglesia "se halla en estado de averse cerrado los arcos" $"$.

Por orden del cabildo, el maestro mayor de obras y el maestro que trabaja en el templo recibieron el encargo de hacer una valoración del gasto que sería necesario invertir para su completa finalización. Estos obreros estimaron que sería suficiente la cantidad de 10.000 ducados para termi-

57. ARMCR, Fondo privado familia Clavero, leg. 197-3, s. f. "Certificación del escribano Diego Romero, sobre varios acuerdos...". Este dato entra en contradicción con lo expresado en el memorial al que ya hemos aludido en varias ocasiones. Según este, la iglesia presentaba unas condiciones que hacían imposible la práctica de culto alguno. Con todo, el memorial no tenía otra finalidad más que presentar una imagen pesimista y deteriorada de la situación para hacer ver la necesariedad de una financiación estable que garantizase un templo para los devotos. La imposibilidad de la celebración de la misa, así como la imperfección de la iglesia, eran elementos, aunque no del todo ciertos, sí indispensables para que el memorial actuase como un efectivo mecanismo de presión ante el deseo del pueblo de ver concluido el proceso constructivo.

58. Ibidem.

59. ARMCR., fondo privado familia Clavero, leg. 178-6, s. f. "Solicitud de Manuel Moreno Mondragón, regidor perpetuo de Ronda, para que libren copia certificada del testimonio del acuerdo del 16 de septiembre de 1700 (...) para sacar a pregón la obra de la Iglesia Mayor y requisitos (...)".

60. Ibidem. 
nar en un plazo de dos años. Con tal veredicto se enviaron requisitorias a las ciudades del Puerto de Santa María, Jaén, Cádiz y Granada, donde se informaba del pregón y de la tasación de las reformas; así mismo, se indicaba que los interesados eran esperados en Ronda el 31 de marzo del año de 1700 , donde podrían ver la construcción y ofrecer sus posturas.

Desde el primer momento los maestros Francisco Gutiérrez Sanguinos y Francisco del Castillo hicieron una proposición en la que ofrecían hacerse cargo de las obras por el precio de 7700 ducados, cantidad algo inferior a la que se había estimado en principio. Los maestros malagueños Benito Ximénez y Joseph de Cascojuela, y el rondeño Bartholomé Martín de Rosas -que en esta fecha trabajaba en la iglesia- también presentaron sus respectivas posiciones, pero, desafortunadamente, desconocemos las cantidades presupuestadas. No obstante, resulta evidente que el criterio de elección era, esencialmente, económico: "se acordó que el remate della se hiciesse en quien mas beneficio hiciesse" ${ }^{61}$.

Las opciones de los maestros de Málaga y Ronda no eran tan apetecibles como la de Francisco Gutiérrez y Francisco del Castillo, que, finalmente, fue seleccionada. Ambos maestros habían trabajado en la catedral de Granada: Castillo como maestro mayor de la misma entre 1697 y 1702, y Gutiérrez como maestro de carpintería del anterior. Su labor allí no pudo terminar de peor modo, pues su pésimo quehacer en una de las bóvedas ejecutadas en el trascoro hizo necesario derribarla, con el consiguiente cese y encarcelamiento de los dos maestros ${ }^{62}$. En especial, se acusaba a Francisco Gutiérrez, dada la nefasta ejecución de todos sus trabajos, lo que llevaría a un distanciamiento con Francisco del Castillo y, años más tarde, al enfrentamiento.

A pesar de ello, e ignoramos si había conocimiento de tales hechos por parte de la autoridades de la ciudad, ambos maestros iban a ser los adalides de la reconstrucción del templo rondeño. Ambos firmaron, con sus respectivos fiadores, la escritura y obligaciones contraídas, pero, curiosamente, las obras fueron ejecutadas por Gutiérrez en solitario, desapareciendo Castillo de la escena hasta 1710, si bien sabemos que, al menos, hasta 1702, permaneció en Granada.

... en 16 de diciembre del año de 1700 con el motivo de averse pregonado y rematado en los suso dichos la obra de la capilla maior de la santa yglesia

61. Ibidem.

62. L. Gila Medina (2005), 203-205. 
mayor de esta ciudad y fabrica de la sacristia y puertas ventanas en presio de siete mil y seteseintos ducados con las calidades y condisiones desa postura se obligo a favor de esta ciudad a executar feneser y concluir la dicha obra en todo lo que faltaba que hazer en dicha ylgesia exepto la soleria previsterio y pulpitos de dicha capilla mayor dentro de dos años...63

El comienzo de la nueva centuria parecía haber sellado el desafortunado destino de la iglesia, pero, la incompetencia de los obreros, junto a una administración poco alabable, volvió a abrir un periodo ominoso de dos décadas antes de que, finalmente, un último impulso constructivo diera al templo su aspecto actual. En 1701, Sancho de Castro cumplió su corregimiento. Con su salida quedaban concluidos, al menos, en apariencia, el mampuesto y la armadura. Sin embargo, la complejidad de los acontecimientos merece un análisis más minucioso.

La escritura de obligación contenía un total de trece condiciones que marcaban, a priori, los pasos de la actuación a seguir, junto con una meticulosa lista de las partes de la fábrica que debían ser reparadas, rematadas, sustituidas o realizadas de nuevo. En líneas generales, las pautas de intervención centraban su atención en la techumbre, armadura y cuerpo de la capilla mayor -junto con las bóvedas de media naranja que dicha parte incluían-, la armadura y colgaderos de la "yglesia antigua", el pedestal de descarga del lado de la Epístola y la elaboración de las dos puertas principales -que debían ser de madera de nogal, adornos en bronce y cerraje y llaves en hierro- y la de la Sacristía ${ }^{64}$. Igualmente, se hace notorio énfasis en la devolución, en el momento de la conclusión, de los andamios y todos aquellos útiles presentes en la obra antes de la intervención; y, como no podía ser de otra forma, en la periodicidad de los pagos. Estos se concretarían en tres plazos: el primero, al comienzo de las mismas, el segundo, en su punto medio, y el tercero, al momento de su finalización; siempre y cuando se cumpliesen las obligaciones fijadas por parte de los maestros con correcta puntualidad. Con tales planteamientos se dio continuación a

63. ARMCR, Fondo privado familia Clavero, leg. 179-16, "Memorial ajustado de los autos seguidos por Antonio de los Ríos, regidor, Andrés de Alba y Juan de Rojas Sandoval, beneficiados de la Iglesia de Ronda. Contra Francisco Gutiérrez Sanguino, maestro a cuyo cargo estaban las obras de la Capilla Mayor y Puente Nuevo. Para llevar originales a la Real Chancillería de Granada en virtud de Real Provisión del 14 de agosto de 1710", fol. 1 (foliación propia, téngase en cuenta a la hora de la consulta del documento).

64. Ibidem, fol. 2. 
las operaciones estructurales en el templo, pero por un tiempo limitado, y con unos resultados cuestionables.

Pronto, en enero de 1703, el cabildo de beneficiados interpuso contra Francisco Gutiérrez Sanguinos un auto de justicia por el incumplimiento de las condiciones y plazos de la escritura. El maestro, más allá de contravenir lo firmado, se embarcó en otros proyectos constructivos con materiales ubicados en la iglesia mayor y destinados a la misma, aunque sin intención de proseguirla "en grave perjuicio de lo obrado" ${ }^{\text {" }}$. Los eclesiales, alterados por la situación, declararon su intención de embargar los bienes y prender a las personas y fiadores de Francisco Gutiérrez en el caso de que la tesitura no llegase a buen puerto. El pueblo, que, en última instancia, financiaba las obras, era, desde siglos pasados, el gran afectado: “...esta muchos días a esperando ver acavada la ylgesia mayor y mas quando considera que no es por falta de medios..."

El maestro, por su parte, reconocía su negativa a reanudar su trabajo en el templo, alegando que tal acto no se produciría hasta que no se le pagasen los más de 12000 reales que, a su parecer, se le debían de los "materiales prevenidos por no deverlos suplir de su propio caudal" 67 . Además, arremetía contra el cabildo eclesiástico, quien:

No es parte para lo que pretende pues a costos y gastos de la dicha obra se ha suplido enteramente por esta ciudad sin que el dicho cavildo aya contribuydo ni pagare obra alguna para ello y solo la ciudad como administradora de los arbitrios consignados para dicho efecto y como principal operante ${ }^{68}$.

En diciembre de 1703, las autoridades eclesiales respondieron al alarife, tomando como intermediarios a la figura del alcalde mayor rondeño y los diputados capitulares, de clara entidad seglar, para canalizar las conversaciones. Sin embargo, Francisco Gutiérrez permanecía anclado en su inmovilismo, alegando la falta de materiales, en especial, de tejas, para la

65. ARMCR, Fondo privado familia Clavero, leg. 197-31, s. f. "Autos del pleito que sigue el Cabildo Eclesiástico de la ciudad de Ronda, contra Francisco Gutiérrez Sanguino, maestro de las obras de la Iglesia Mayor de ella. Para que acabe dicha obra, ante el escribano mayor de cabildo Isidro de Padilla".

66. ARMCR, Fondo privado familia Clavero, leg. 179-16, "Memorial ajustado de los autos seguidos por Antonio de los Ríos, regidor, Andrés de Alba y Juan de Rojas Sandoval, beneficiados de la Iglesia de Ronda. Contra Francisco Gutiérrez...", fol. 4.

67. Ibidem, fol.5.

68. Ibidem, fol.5. 
consecución, lo que era desmentido por la facción opuesta, que sostenía con firmeza la existencia de los materiales y maderas necesarias. Por añadidura, recriminaban su actuación en las dependencias de las monjas descalzas del Patrocinio, en detrimento de las obras del templo.

Ante tal panorama, el cabildo de beneficiados decidió poner en marcha los mecanismos necesarios para embargar los bienes del empecinado maestro y sus fiadores, recurriendo al Consejo de Castilla si fuese necesario; así como la búsqueda de un nuevo maestro que se hiciera cargo de las tareas desechadas por su predecesor y enmendara los daños que pudiera haber cometido $^{69}$.

Las conversaciones infructuosas con el maestro de obras llegaron a su fin en las postrimerías de 1703. Entre tanto, las obras seguían estancadas y no sería hasta 1707 cuando los procedimientos se materializaron en acciones firmes en beneficio de la prosecución de la edificación. En 1706 se procedió a recurrir al Consejo de Castilla solicitando una real provisión que instase a Francisco Gutiérrez - quien, ahora, consideraba su tarea concluida- a cumplir sus obligaciones bajo graves penas y apercibimiento. Desde tales instancias superiores, el corregidor concedió desde abril de 1707 el plazo de un mes para el colofón del asunto ${ }^{70}$.

No obstante, aunque el maestro tarde o temprano modificase su comportamiento y retomase su actividad, esta no estaba inmune a defectos materiales múltiples, lo que nos revela una segunda faceta del personaje: la ineptitud galopante para con su oficio. Los numerosos problemas en la techumbre sembraron un mar de dudas que debían ser confirmadas por un maestro propiamente dicho. Con tales intenciones, el corregidor Antonio de los Ríos, en la búsqueda de un maestro mayor de alguna catedral andaluza, contactó con la ciudad de Sevilla, que mandó a su respectivo alarife, Blas Sancho. En su reconocimiento de la iglesia declaró que las obligaciones contraídas no habían sido cumplidas y que la estructura presentaba críticas dolencias, sobre todo hacía referencia al preocupante estado de las azoteas de la iglesia y capillas del altar mayor, heridas por los temporales y que recalaban interiormente ${ }^{71}$.

Una condición contenida en la escritura primigenia mencionaba claramente que las mejoras y desperfectos corrían a cargo del firmante, tal y como era el caso. El maestro mayor sevillano recomendaba a Francisco

69. Ibidem, fol. 4.

70. Ibidem, fol. 6 .

71. Ibidem, fol. 7. 
Gutiérrez el uso de materiales de mejor calidad que garantizasen la impermeabilidad de las capillas. Con tales indicaciones, y con 1.200 reales de vellón procedentes de los arbitrios, quedaba obligado a realizar las mejores y clausurar la solería antes del fin de agosto de 1707. Si bien el maestro pareció intervenir en la reparación de las capillas, los arreglos practicados no parecían solucionar el contratiempo de la filtración del agua.

En suma, el incumplimiento de la colocación de las puertas motivó el recurso a la Real Chancillería de Granada que falló a favor del cabildo dando un plazo máximo hasta febrero de 1708, que, a todas luces, no cumplió. Para más inri, se ausentó a su Granada natal y, aunque a su retorno, retomó, en vano, su tarea, ambos cabildos -eclesiástico y secular- optaron por medidas más drásticas. Se dictó una orden de encarcelamiento, embargo y venta de sus bienes a la par que se nombraron nuevos maestros, con insistencia en que fuesen personas inteligentes: Francisco del Castillo y Juan Rodríguez, maestros de albañilería, Francisco Bautista, maestro carpintero, y Domingo Delgado, maestro latonero ${ }^{72}$.

El nuevo equipo estimó los costes en sus respectivas parcelas y se dio continuidad a los trabajos, pero, pronto, se percibió una ingrata y alarmante sorpresa de la que no se tenía constancia y que volvía a salpicar al maestro encarcelado:

se avia reconosido que lo obrado por dicho maestro [Francisco Gutiérrez] estaba falsificado y con reconosido riesgo de caerse con mucha brevedad por averse hecho contra regla la armadura de las bobedas de que avia resultado aver hecho movimiento las paredes prensipales de las quales se avian desmentido y apartado dichas bobedas y que no teniendo la entibasion suficiente no podian mantenerse y estaban espuestas a aruinarse con graves daños y pedidas como se dejaba reconoser ${ }^{73}$.

Una vez informados de la situación los cabildos implicados se proveyó un auto para el reconocimiento de la obra. Por parte de la ciudad, asistieron Francisco Bautista y Pedro Bello, maestro de la villa de Morón; y en nombre del controvertido preso, Juan Pérez Barrios, en lo respectivo a albañilería,

72. Ibidem, fols. 12-14. A pesar de que el maestro cantero Francisco del Castillo aparece junto a Gutiérrez Sanguinos como ganador del primer pregón de la obra en 1700, se desvincula de la misma y del referido maestro. No será hasta este momento cuando tome papel en la obra y, con más intensidad, durante la siguiente década en las actuaciones de la solería del templo.

73. Ibidem, fol. 15 . 
y Juan Redondo, a carpintería. Previsiblemente, las declaraciones de ambos bandos fueron opuestas y contradictorias. Mientras que los primeros pronunciaron tajantemente la inseguridad de la armadura y el perturbador vaivén de las paredes a consecuencia de una errada acción en las bóvedas, los segundos adujeron una posible reforma de las mismas y el refuerzo de la armadura, si bien en un plano que excluía la estricta necesariedad ${ }^{74}$. La abismal discrepancia hizo que el parecer de los maestros dispuestos por Gutiérrez Sanguinos fuese tildado de interesado y carente de valor ante los patentes estragos en la fábrica. El desenlace pasaba nuevamente por escuchar el juicio de algún maestro de prestigio, de alguna catedral de Andalucía, para valorar los precios, materiales y arreglos ineludibles para la seguridad del conjunto ${ }^{75}$.

Entre tanto, el polémico encarcelado irrumpió en su defensa personal. Reclamaba su inmediata excarcelación y poder hacer una declaración propia que no estuviese impulsada por el odio, pues, a su humilde parecer, el cumplimiento de sus obligaciones había engendrado una obra segura y acabada. En suma, reprochaba al cabildo eclesiástico los acaudalados gastos inútiles, el excesivo conocimiento teórico -pero no práctico- de Francisco Bautista y sacaba a relucir la ofensa que suponía hacia su persona la terquedad de los cabildos en la busca de "personas inteligentes" para la obra. Más aún cuando su prestigio quedaba respaldado por sus actuaciones en la catedral granadina, si bien -como no desveló- fue un ejercicio que no estuvo falto de desaciertos ${ }^{76}$. A pesar de todo, las autoridades competentes se anclaron en la idea del veredicto de un maestro reconocido, independiente e imparcial. Tras ello, Francisco Bautista, amparado por el cabildo eclesiástico, podría enmendar los achaques que padecía el templo ${ }^{77}$.

Francisco Gutiérrez nombró por su parte a Francisco García Fulgencio, maestro mayor de cantería y carpintería de la ciudad de Granada, al tiempo que solicitaba que el concejo no eligiese a Francisco Bautista, ni a Cristóbal González por la aversión mutua generada. Ayuntamiento y cabildo religioso

74. Ibidem, fols.16-17.

75. Ibidem, fols. 18 .

76. Ibidem, fols. 19-21. Ya abordamos antes el incierto pasado de Francisco Gutiérrez en Granada. Transcribimos literalmente el siguiente fragmento con la intención de complementar lo ya tratado: "...avia errado dos veses la obra de la santa yglesia de Granada en la bobeda que llaman el anillo porque se le avia despedido de ella y a tener notisia la ciudad [de Ronda] de su poca inteligencia y ierros que avia executado en dicha santa yglesia ubiera buscado a otro maestro de su maior satisfacion..."

77. Ibidem, fols. 21-22.

(C) Baetica. Estudios Historia Moderna y Contemporánea, 38, 2018, 47-77.

Facultad de Filosofia y Letras, Universidad de Málaga. Departamento de Historia Moderna y Contemporánea 
optaron por Felipe Unzurrunzaga, maestro mayor de la ciudad de Málaga y su iglesia, y Salvador de Amaya, maestro carpintero de Ronda; pero se oponían a la presencia de maestros granadinos ${ }^{78}$. Tras varias propuestas de maestros por ambas partes, censurados mutuamente, el corregidor adjudicó el reconocimiento a Felipe de Unzurrunzaga y a un maestro que mandase la ciudad de Sevilla, que, finalmente, fue Leonardo de Figueroa ${ }^{79}$. Ambos visitaron exhaustivamente las partes problemáticas y emitieron un dictamen firme: la armadura presentaba un estado de insuficiencia, debilidad y extrema pesadez que amenazaba desastre; la media naranja recibía un peso insoportable, junto con las paredes de las capillas, que también necesitaban reforma; y las puertas estaban oblicuas y fuera de su marco ${ }^{80}$. Ningún reparo podría subsanar el estropicio presente, en especial, el de la techumbre.

A juzgar por las acciones posteriores, el extracto de esta declaración - con la autoridad y reputación de los maestros- no tuvo un gran valor a la hora de tomar la dirección de actuación. De hecho, tras ella, tuvo que pasar un año, hasta julio de 1709 para que el marqués de la Casa de Pabón, corregidor rondeño, estimase oportuno invitar a Francisco Gómez, perteneciente a la Compañía de Jesús, para que examinase la obra al ser una personalidad muy docta en cuestiones arquitectónicas. Este consideró que solo eran precisos unos remiendos en la armadura, más allá de volver a ejecutar todo de nuevo.

Sin embargo, no sería el último en inspeccionar el templo, pues, en diciembre igualmente opinó Laurencio Fernández Yglesias, quien emitió un juicio similar al de los maestros de Sevilla y Málaga. El desvío de los muros se debía a la mala disposición de la armadura, que había que quitar, si bien se podían hacer ciertos reparos en otras secciones y en la media naranja ${ }^{81}$. La concreción de este último de los costes en 10000 ducados y

78. La vinculación de Francisco Gutiérrez a las actividades arquitectónicas de la ciudad de Granada y su obispado constituyen el argumento sobre el que las autoridades seglares rondeñas evitan en todo momento la venida de maestros de dicha tierra por sus evidentes contactos con el maestro Gutiérrez. En oposición, los maestros que reconocen la obra proceden del obispado de Málaga, y en mayor medida del de Sevilla, a pesar de la vinculación de Ronda al primero, lo que demuestra el prestigio de estos. M. M. Fernández Martín (2001), 99.

79. ARMCR, Fondo privado familia Clavero, "Memorial ajustado de los autos seguidos por Antonio de los Ríos, regidor, Andrés de Alba y Juan de Rojas Sandoval, beneficiados de la Iglesia de Ronda. Contra Francisco Gutiérrez...", leg. 179-16, fols. 27-28.

80. Ibidem, fol. 29.

81. Ibidem, fols. $30-32$. 
una duración de 6 o 7 meses motivaron al corregidor para sacar las obras a pregón en 1710 por segunda vez en menos una década.

Pero antes de adentrarnos de lleno en la fase final que dio luz al templo, resulta imprescindible analizar la situación de Gutiérrez Sanguinos, quien, tras meses en prisión, pudo salir gracias a las fianzas depositadas. Durante el tiempo que pasó entre rejas se sucedieron varias declaraciones, como se detalló previamente, $\mathrm{y}$ en las que el maestro no pudo tomar partida, directa ni indirectamente. Algunas de ellas no arremetían con tanta fuerza contra el preso como otras -es más, incidían en posibles reparos, lejos de una reconstrucción íntegra- y se indica que aquellas que lo perjudicaban tenían detrás la "insuniacion y persuasion del dicho Francisco del Castillo y demas sus aliados", interesados en la condena y desacreditación de su antiguo compañero $^{82}$. No debemos olvidar que Francisco del Castillo, junto con una serie de trabajadores, continuaron sus labores en la iglesia tras la encarcelación de Gutiérrez -y económicamente a su costa-, de forma paralela a las declaraciones.

La percepción de la concatenación de intereses múltiples puede explicar la insistencia del corregidor en que la obra fuera examinada por distintos maestros antes de dictaminar los términos oficiales en que habría de hacerse el pregón. Las condiciones de este serían, finalmente, acorde a la declaración del último maestro. De tal forma, que quien hiciera posturas debía saber que los trabajos a realizar serían: rebajar y reforzar con tirantes la armadura, ejecutar nuevamente la media naranja, y construir una nueva capilla con su respectiva bóveda de ladrillo debido al alto coste de la cantería ${ }^{83}$.

Nuevamente, se ponían en marcha los procedimientos ya practicados en 1710, pero sin olvidar que la vuelta al comienzo de todo, en cierto modo, recaía bajo la responsabilidad de Francisco Gutiérrez. Si ya se habían materializado contra él diversas instancias judiciales y se habían embargado sus bienes, sería en estos momentos, cuando, seriamente, se recurriese a la Real Chancillería de Granada. La fundamentación de tal acto descansaba en la oscilación de las paredes en momentos preliminares a la entrada de Francisco del Castillo en la fábrica. Este pedía que para evitar el sufrimiento de los muros se interviniese sin demora en la media naranja. Los gastos debían ser abonados por Gutiérrez, quien se negaba a tal pago, aduciendo los más de 10000 ducados perdidos y el atentado contra su buena reputación en este proceso ${ }^{84}$.

82. Ibidem, fol. 35 .

83. Ibidem, fol. 33 .

84. Ibidem, fols. 34-35. 
En cualquier caso, el tribunal granadino emitió una carta ejecutoria condenando al pago de 580 reales de los reparos. Tal retribución dio lugar a la venta de las propiedades confiscadas para que estas suplieran el dinero a deber. No obstante, la lentitud de los procedimientos hizo que esta tarea no culminase hasta entrada la década venidera. Asimismo, se tuvo que hacer frente a los gastos generados por las propiedades incautadas y por los viajes a Granada para el seguimiento del pleito, que fueron sufragados a costa de los arbitrios ${ }^{85}$.

Independientemente de las cuestiones de la justicia con el maestro que tanto habían atrasado la terminación de la iglesia y que aún se dilatarían unos años, si bien parecían zanjadas, el referido pregón siguió adelante. La primera posición en 1710 resultó ser de Francisco del Castillo, quien ofrecía finiquitar el conjunto completo por 5500 ducados. La segunda proposición fue hecha en 1711 por Sebastián de Espada y Bartolomé Pérez, en nombre de José Páez de Carmona, todos maestros ecijanos, con una bajada de 500 reales respecto a la anterior, la cual resultó ganadora $^{86}$. Por el contrario, el arranque no se produjo de forma inminente, pues hasta 1718 no se firmaron las obligaciones ni se formalizaron los avales indispensables ${ }^{87}$.

En este intervalo temporal advertimos la intervención de otros tantos maestros. El más destacable es, irremediablemente, Francisco del Castillo, quién pareció obligarse a la ejecución de la solería, pero, en fecha de 1714, y habiendo recibido parte de los pagos, encontró la muerte. Sus herederos y fiadores tuvieron que lidiar con la ciudad por el hecho de que Castillo había recibido pagos aun cuando la obra no había sido terminada debido a su fallecimiento. Por su parte, Felipe de Unzurrunzaga, el que otrora reconocía la obra, en 1716, se obligaba por 37000 reales a realizar el presbiterio y solería y la unión de la vieja y nueva fábrica, junto a otras tareas de menor entidad ${ }^{88}$. No obstante, estas actuaciones no debieron ser concluyentes pues, en 1723, quedaba derribar una pared que dividía la capilla mayor, y "que los beneficiados y fabricas de dicha iglesia abiliten los medios necesarios como es de su

85. ARMCR, Fondo privado familia Clavero, leg. 197-3, s. f. "Certificación del escribano Diego Romero, sobre varios acuerdos...".

86. M. M. Fernández Martín (2001), 98-99.

87. Ibidem, 100 .

88. R. Camacho Martínez (1981), 418-419; R. Camacho Martínez (2000), 301. La participación del referido maestro también queda constada en las notas manuscritas de Juan Temboury Álvarez, vide: S. RAmírez GonzÁlez (2006), 61. 
obligacion para retablos, adorno y demas que se necesita para celebrar en ella el divino culto" ${ }^{89}$.

El estado eclesiástico quiso contribuir, aunque de forma algo somera en la finalización de templo; y esto se concretó en un aspecto que resultaba tan trascendental como lo era la decoración artística que habría que brindar al templo. En 1724, de los 30000 reales considerados para finiquitar, el cabildo catedralicio malagueño aportó $16000^{90}$. Atendiendo a los datos facilitados por Moreti, un año antes se había encargado el altar mayor y presbiterio a Esteban de Salas bajo los planos de fray Miguel de los Santos. La falta de información primaria en este aspecto no nos permite salir de la duda, pero en cualquier caso resulta evidente el estado prácticamente finalizado. Únicamente cabe destacar la apertura de una nueva puerta en 1766 y la aportación de 32683 reales y 29 maravedíes en 1796 por el obispo de Málaga Manuel Ferrer y Figueredo para gastos de enlosado y bóveda ${ }^{91}$.

Tras medio siglo de construcciones, destrucciones, interrupciones, problemas estructurales, pleitos contra los maestros y pregones de obras, el largo proceso constructivo parecía a su fin para que de nuevo el templo pasara a ser un santo lugar estable para el culto y los oficios religiosos.

\section{CONCLUSIÓN}

El análisis del memorial histórico de iglesia de la Encarnación de Ronda nos permite calificarla, de entrada, como un templo, que, al menos, debe ser tildado de desafortunado. Desde los inicios de la construcción de la sociedad cristiana en las antiguas tierras del infiel, se postuló como templo principal, no solo por su tamaño, sino por el envidiable lugar que ocupaba en el núcleo primigenio de la ciudad y su consiguiente importancia en la vida de la urbe. Por lo demás, la finalización de la fábrica -iniciada en el siglo XVI- se convertiría en un anhelado deseo de sus vecinos a lo largo de toda la Edad Moderna.

Pronto, los problemas de crecimiento poblacional y la necesidad de ampliar la fábrica quedarían empequeñecidos ante la grandiosidad del sinfín de catástrofes de variada tipología que damnificaron la estructura sagrada. Si bien en el quinientos la historiografía local no deja de encerrar cierta imprecisión y titubeo, el fuerte soporte documental posterior nos muestra

89. ARMCR, fondo privado familia Clavero, leg. 196-23, s. f. "Borradores y copia del memorial sobre la mala administración de los arbitrios...".

90. R. Camacho Martínez (1981), 419.

91. J. J. Moreti (1993), 720-721. 
abierta y notoriamente un templo destinado a la ruina, al fracaso, y por ende, a la difícil faceta de cumplir lo que canónicamente un templo debe desempeñar: culto y administración de los sacramentos.

Las continuas destrucciones de la iglesia en una sociedad tan profundamente religiosa debieron provocar un tremendo impacto en la mentalidad popular, en el contexto del caos sembrado por una catástrofe, y más aún, atendiendo a la categoría del inmueble afectado. De todo ello extraemos una firme tesis: la fuerza e insistencia del pueblo, su sentimiento religioso y su actitud devota fueron el motor que en todo momento impulsó la reconstrucción. Si bien las autoridades civiles y eclesiásticas gestionaron y administraron tales tareas en todo momento, los costos fueron asumidos por la mayoría devota: el pueblo.

Una vez que el convulso e intenso horizonte de calamidades naturales pareció apaciguarse con la llegada de la centuria ilustrada, devinieron otras circunstancias perjudiciales, de diferente índole, y cuyo impacto en la alborotada lucha de la iglesia por la supervivencia nos permiten clasificarla, ahora, como catástrofes humanas. De tal modo, la fortuna no estaba del lado del templo cuando el ganador del primer pregón retardaría hasta más de dos décadas la tan añorada iglesia para la ciudad del tajo.

Llegado ese momento, y bien entrado el siglo XVIII, se produjo el acontecimiento no contemplado en siglos anteriores: la iglesia se había terminado. Temas tan trascendentales para la sociedad moderna como la mentalidad, la vida cotidiana, la fiscalidad o la estructura urbana se conjugan en esta historia. La iglesia como eje vertebrador de la sociedad moderna, en este caso local, se nos delata una vez más.

\section{BIBLIOGRAFÍA}

Alberola Romá, Armando (2012), "Terremotos, memoria y miedo en la Valencia de la Edad Moderna", Estudis: revista de historia moderna, 38, pp. 55-75.

Acién Almansa, Manuel (1977), Ronda y su Serranía en tiempo de los Reyes Católicos, tomo I, Universidad, Málaga.

Adroder, Andrés, Aguayo De Hoyos, Pedro, y Ruiz, C. (1991), "Informe de la excavación de urgencia en el solar $\mathrm{n}^{\circ} 5$ de la calle Juan Bosco de Ronda. 1986", en Anuario Arqueológico de Andalucía 1991, tomo III, Consejería de Cultura de la Junta de Andalucía, Cádiz, pp. 407-412.

Aguayo De Hoyos, Pedro y Castaño Agüilar, José Manuel (2000), "Estado de la cuestión sobre la estructura urbana de la ciudad de Ronda en época medieval", en L. CARA Barrionuevo (coord.), Ciudad y territorio en Al-Andalus, Athos-Pérgamos, Granada. 
Aguilar García, María Dolores (1979), Málaga Mudéjar. Arquitectura religiosa y civil, Universidad, Málaga.

Amador de los Ríos, José (1907), Catálogo de los Monumentos Históricos y Artísticos de la Provincia de la Málaga II formado en virtud de R.O de 22 de Enero de 1907, ejemplar mecanografiado (Biblioteca Virtual de Andalucía: http:/www.bibliotecavirtualdeandalucia.es/catalogo/consulta/registro. cmd?id=1014329).

Camacho Martínez, Rosario (1981), Málaga barroca: arquitectura civil y religiosa de los siglos XVII y XVIII, Universidad, Málaga.

— (2000), "El arquitecto vasco Felipe de Unzurrunzaga (1654-1740) y sus intervenciones en la arquitectura religiosa en Andalucía", Ondare, 19, pp. 293-303.

Castaño Agüllar, José Manuel (2006), “Antigüedad Tardía y Alta Edad Media en la Serranía de Ronda”, en B. Nieto González, J. M. Castaño Agüilar y J. Padial Pérez, Historia de Ronda. Desde la romanización a la época musulmana. I Congreso de Ronda, Ayuntamiento, Ronda, pp. 133-192.

De Pineda, Juan (1715), Chronologia hospitalaria y resvmen historial de la sagrada religion del patriarca S. Juan de Dios, Imprenta de Francisco Antonio de Villadiego, Madrid.

Fariñas del Corral, Macario (2014), Antigüedades de Ronda (edición, estudio introductorio y transcripción a cargo de Rafael Valentín López Flores y Sergio Ramírez González), Ediciones Pinsapar, Ronda.

Fernández Basurte, Federico (1992), "Reacciones piadosas colectivas ante las calamidades públicas en la Málaga del siglo XVII. La epidemia de 1649 y el terremoto de 1680", en L. C. Álvarez Santaló y C. M. Cremades Griñán (eds.), Mentalidad e ideología en el Antiguo Régimen. II Reunión Científica. Asociación de Historia Moderna, vol. 2, Universidad, Murcia, pp. 211-224.

García De La Leña, Cecilio (1789), Conversaciones Históricas Malagueñas, Imprenta de la Dignidad Episcopal, Málaga.

García Torres, Adrián (2018), "La religiosidad popular frente a las adversidades climáticas y naturales en los siglos XVII-XVIII”, en E. Serrano Martín y J. GASCón Pérez (eds.), Poder, sociedad, religión y tolerancia en el mundo hispánico, de Fernando el Católico al siglo XVIII, Institución Fernando el Católico, Zaragoza, pp. 787-800.

Gila Medina, Lázaro (2005), "La última etapa constructiva: de 1650 a 1704” en L. Gila Medina (coord. y ed.), El libro de la Catedral de Granada, Cabildo metropolitano de la ciudad de Granada, Granada, vol. I, pp. 211-237.

Guillén Robles, Francisco (1985), Historia de Málaga, II, Arguval, Málaga.

León Vegas, Milagros (2007), Dos siglos de calamidades públicas en Antequera. Crisis epidémicas y desastres naturales (1599-1804), Ayuntamiento, Antequera.

López de Coca Castañer, José Enrique (1977), La tierra de Málaga a fines del siglo $X V$, Universidad, Granada. 
López-Guadalupe Muñoz, Miguel Luis y García Bernal, José Jaime (2010), “El temblor de 1680, entre tradición retórica y pedagogía moderna", Baetica. Estudios de Arte, Geografía e Historia, 32, pp. 339-353.

Llordén, Andrés (1962), Arquitectos y canteros malagueños. Ensayo Histórico Documental (Siglos XVI-XIX), Ediciones Real Monasterio de El Escorial, Madrid.

Lozano Gutiérrez, Francisco (2005), Historia de Ronda, Editorial La Serranía, Ronda. (Reimpresión facsímil del original de 1905)

Miró Domínguez, Aurora (1987), Ronda. Arquitectura y urbanismo, Confederación Española de Cajas de Ahorro, Ronda.

Miró Domínguez, Aurora y Camacho Martínez, Rosario, (1994) "El abastecimiento de agua a Ronda", Boletín de Arte, 15, pp. 109-128.

Moreti, Juan José (1993), Historia de Ronda (Reproducción facsímil del original de 1867), Fundación Unicaja, Málaga.

Pereiro Barbero, Presentación (1985), "Los efectos del terremoto de 1680 en Málaga”, Jábega, 50, pp. 34-39.

Ramírez González, Sergio (2006), El monasterio de clarisas de Santa Isabel de Ronda. Historia y Arte de una clausura franciscana, Editorial la SerraníaReal Maestranza de Caballería de Ronda, Ronda.

Reder Gadow, Marion (2006), "Alarde en Ronda y su tierra (Año 1691) (1 Parte)" Baetica. Estudios de Arte, Geografía e Historia, 28, pp. 477-502.

Rodríguez Martínez, Francisco (1977), La Serranía de Ronda. Estudio geográfico, Confederación Española de Cajas de Ahorro, Málaga.

Rubia Lozano, Adela (2017), "Málaga y el terremoto de 1680", en M. I. Vila González (coord.), Un siglo en doce meses. El siglo XVII. Documentos procedentes del Archivo Municipal de Málaga, Ayuntamiento, Málaga, pp. 175-165.

Rueda Ramírez, Pedro José y Fernández Chaves, Manuel (2008), "El terremoto como noticia: relaciones de sucesos y otros textos del temblor de 1680", Estudios sobre el mensaje periodístico, 14, pp. 581-604.

Sánchez López, Juan Antonio y Ramírez GonzÁlez, Sergio (2003), "La Real Colegiata de Santa María la Mayor: marco monumental para una exposición", Exposición el hombre de la Sínode. Juan Manuel Miñarro López, Fundación Unicaja, Ronda, pp. 21-28.

Sierra De Cózar, Pedro (2009), Ronda en el Siglo XVIII según las Respuestas Generales del Catastro de Ensenada, Editorial La Serranía, Ronda.

Sierra De Cózar, Pedro y Sierra Velasco, José Eugenio (2011), La sed de Ronda, Editorial La Serranía, Ronda.

Torres BalbÁs, Leopoldo (1944), "La Acrópolis musulmana de Ronda", Al Andalus, 9, pp. 449-481.

VinCENT, Bernard (1985), "Las epidemias en Andalucía durante el siglo XVI”, en B. Vincent, Andalucía en la Edad Moderna: economía y sociedad, Diputación Provincial, Granada, pp. 39-49.

VINCENT, Bernard (1986), “El terremoto de Málaga de 1680”, Historia 16, 11, pp. 27 - 